\title{
Mechanical and Fresh State Properties of Medium Strength Self-Compacting Concrete (SCC) Containing Polypropylene Fibres
}

\author{
Anas Alalwany ${ }^{1}$, Noridah Mohamad ${ }^{1, *}, A . A . A$. Samad $^{1}$, and W. I. Goh ${ }^{1}$ \\ ${ }^{1}$ Department of Structure and Material Engineering, Faculty of Civil and Environmental Engineering, \\ Universiti Tun Hussein Onn Malaysia, Parit Raja, 86400 Batu Pahat, Johor
}

\begin{abstract}
Due to the rising demand of infrastructure development, concrete has been one of the vital ingredients in this field considering its flexibility to mould any structural shape and design. This paper investigates the effect of adding polypropylene fibres on the mechanical and fresh properties of self-compacting concrete (SCC). The mechanical property tests were conducted on various SCC specimen which include cubes, cylinders and beams to determine its compressive strength, splitting tensile strength and flexural strength of concrete. The workability of selfcompacting concrete in terms of viscosity is determined from slump flow test (Diameter and T500), and V-funnel. The results indicated that the addition of polypropylene fibres improved the mechanical properties of $\mathrm{SCC}$ at almost every volume fraction considered in this study. It was also observed that the addition of $0.1 \%$ fibre significantly enhanced the splitting tensile strength and flexural strength of concrete. Finally, the overall results indicated that introducing fibres to concrete would result in a noticeable decrease in workability and fresh state properties.
\end{abstract}

\section{Introduction}

In response to enhance the ordinary concrete, there is a rising need for further development to self-compacting concrete (SCC). In 1988, it was the very first investigation that focused to accomplish concrete structures with high level of durability. Accordingly, a range of researches were conducted, whereas the concrete was used for practical purposes by large construction companies based in Japan [1].

SCC is a non-segregated concrete free of air and spaces that adjusts to any formwork [1]. Without such vibration process, it flows constantly by the means of its weight, thoroughly packing up the formwork and accomplishing full compaction status even with a very packed reinforcement. SCC is utterly one of the most adapted concrete particularly with the use of some chemicals such as super plasticizers and other viscosity modifiers, and minerals i.e. fly ash, slag, silica fume as admixtures in the concrete. Advantages of SCC include faster construction, reduction in manpower, easier placing, uniform and

*Corresponding author: noridah@uthm.edu.my 
complete consolidation, better surface finishes, improved durability, increased strength and safer working environment [1].

Polypropylene fibres (PP) were first suggested as an admixture to concrete in 1965, where it was applied in the constructing of anti-blast buildings in the US [2]. The fibre has subsequently been improved further and at present it is used either as short discontinuous fibrillated material for production of fibre reinforced concrete or a continuous mat for production of thin sheet components. It is used in concrete engineering for its enormous advantages such as ductility, calibre, and dispersal so it can pin down any possible cracks [3]. Additionally, it has been proved that adding fibres to concrete enhances formability and bending strength [4].

In this paper, fresh state and mechanical properties of SCC incorporating with PP are thoroughly discussed. The fresh state properties of SCC were determined by using a specific mixture design provided from many trial designs. The mechanical properties of SCC namely; concrete flexural strength, splitting tensile strength and compressive strength were estimated by conducting a compressive strength test on SCC cubes cylinders and beams. All tests were conducted according to the British Standard code [5, 6]. SCC concrete incorporating PP is able to produce concrete with compressive strength higher than conventional concrete.

\section{Materials and method}

Self-compacting concrete specimens were formed by mixing cement, water, fine aggregate, coarse aggregates, PP and super plasticiser. A Mega Mesh I PP fibre was utilized in this experiment as shown in Fig. 1. Mega Mesh I is used as concrete enhancing material in two mixing designs. PP fibre is considered to offer maximum anchorage that in turn boosts the resistance to pull-out with its three dimensional planes.

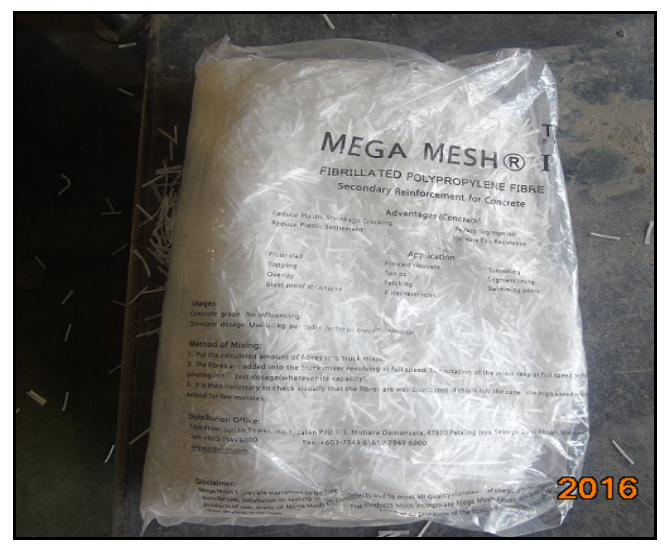

Fig. 1. Mega Mesh I.

\subsection{Mixture design}

A combination of three experiments was tested within the design base on previous work done by Sonebi [7]. $0.2 \mathrm{~m}^{3}$ of concrete was mixed in each experiment as shown in Table 1 
Table 1. Concrete mix design.

\begin{tabular}{|c|c|c|c|c|c|c|c|}
\hline $\begin{array}{l}\text { PP fibre } \\
(\mathrm{kg} / \mathrm{m} 3)\end{array}$ & $\begin{array}{l}\text { Cement } \\
(\mathrm{kg} / \mathrm{m} 3)\end{array}$ & $\begin{array}{l}\text { FA } \\
\left(\mathrm{kg} / \mathrm{m}^{3}\right)\end{array}$ & $\begin{array}{l}\text { PP } \\
\text { Fiber } \\
(\mathrm{kg} / \mathrm{m3})\end{array}$ & $\begin{array}{l}\text { Sand } \\
(\mathrm{kg} / \mathrm{m} 3)\end{array}$ & $\begin{array}{l}\text { Coarse } \\
\text { aggregate } \\
\left(\mathrm{kg} / \mathbf{~ m}^{3}\right)\end{array}$ & $\begin{array}{l}\text { SP } \\
(\mathrm{kg} / \\
\left.\mathrm{m}^{3}\right)\end{array}$ & $\begin{array}{l}\text { Water / } \\
\text { (Cement } \\
\text { +FA) } \\
\text { Ratio }\end{array}$ \\
\hline 0 & 270 & 140 & 0.00 & 740 & 850 & 2 & 0.55 \\
\hline 0.45 & 270 & 140 & 0.45 & 740 & 850 & 2 & 0.55 \\
\hline 0.9 & 270 & 140 & 0.90 & 740 & 850 & 2 & 0.55 \\
\hline
\end{tabular}

Note; PP: Polypropylene, FA: Fly ash, SP: Super plasticizers.

\subsection{Laboratory tests}

The laboratory tests conducted in this study are categorized into two types; namely, fresh state property test and mechanical strength test on SCC cubes and cylindrical specimens containing PP. Fresh concrete testing was selected to investigate the main properties of the fresh mixture in addition to estimate the mixture's passing ability, resistance to segregation and filling ability. Tests were as follows: V funnel, slump flow and slump flow T50. On the other hand, the mechanical strength tests included comprehensive strength tests on the SCC cubes and cylinders to determine the compressive, splitting tensile and flexural strengths for each selected mixture.

\section{Results and discussion}

\subsection{Fresh and physical properties}

\subsubsection{Slump flow test}

From the slump flow test, the fibre distribution was found to be uniform. All mixtures have good fluidity and exhibited self-compacting characteristics. Table 2 demonstrates the data for workability of the fresh SCC as achieved from slump flow tests (Slump flow diameter and $\left.\mathrm{T}_{500}\right), \mathrm{T}_{5 \mathrm{~min}}$ for various percentage of PP used.

Table 2. The result of slump flow test and Slump flow $\mathrm{T}_{500}$ test.

\begin{tabular}{|c|c|c|c|c|}
\hline Sample & $\begin{array}{c}\text { Max } \\
\text { Diameter,dmax } \\
(\mathrm{mm})\end{array}$ & $\begin{array}{c}\text { Slump Flow Test } \\
\text { Perpendicular } \\
\text { Diameter, } \mathrm{d}_{\text {perp }}(\mathrm{mm})\end{array}$ & $\begin{array}{c}\text { Average } \\
\text { Diameter, } \\
\mathrm{S}(\mathrm{mm})\end{array}$ & $\begin{array}{c}\text { T500 } \\
(\mathrm{s})\end{array}$ \\
\hline Mix 1 & 540 & 560 & 550 & 6 \\
\hline Mix 2 & 480 & 420 & 500 & 4 \\
\hline Mix 3 & 360 & 300 & 430 & 2 \\
\hline
\end{tabular}

Results in Table 2 and Fig. 2 show that for the SCC control mixture, the slump flow spread diameter was $550 \mathrm{~mm}$ while for $\mathrm{T}_{500}$ it achieved $500 \mathrm{~mm}$ flow spread. With the presence of $0.9 \mathrm{~kg} / \mathrm{m}^{3} \mathrm{PP}$, the slump flow spread diameter and $\mathrm{T}_{500}$ showed decrement up to $430 \mathrm{~mm}$ and $2 \mathrm{~s}$, respectively. Mix 2 recorded optimum workability compared to Mix 3. However, the spreading range obtained for Mix 2 was within the acceptable range, which is from $500 \mathrm{~mm}$ to $700 \mathrm{~mm}[8]$. 


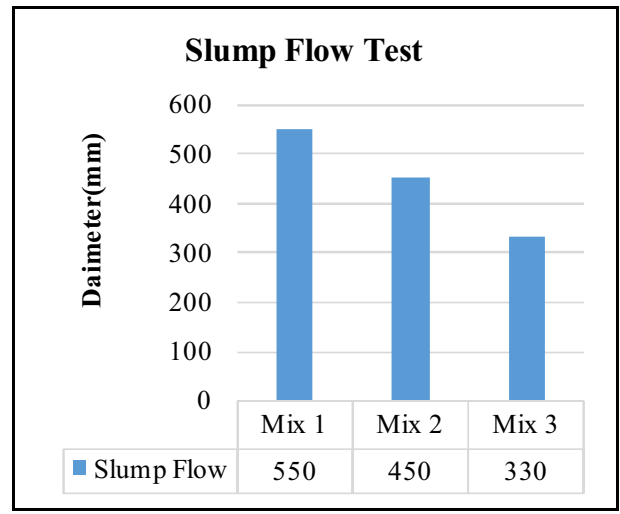

Fig. 2. The bar graph of slump flow result.

\subsubsection{V-funnel test}

In this experiment, the funnel was filled with the concrete and flow time was accordingly taken for it to flow through the apparatus. The main reason for conducting the V-Funnel test was to assess the stability of SCC mixture [9]. In one study, it was found that a less than 6 second flow time is significantly giving high quality to the SCC [10]. See Table 3 and Fig. 3.

Table 3. The result of V-funnel test.

\begin{tabular}{|c|c|}
\hline Experiment & V-Funnel (sec) \\
\hline Mix 1 & 5 \\
\hline Mix 2 & 8 \\
\hline Mix 3 & 10 \\
\hline
\end{tabular}

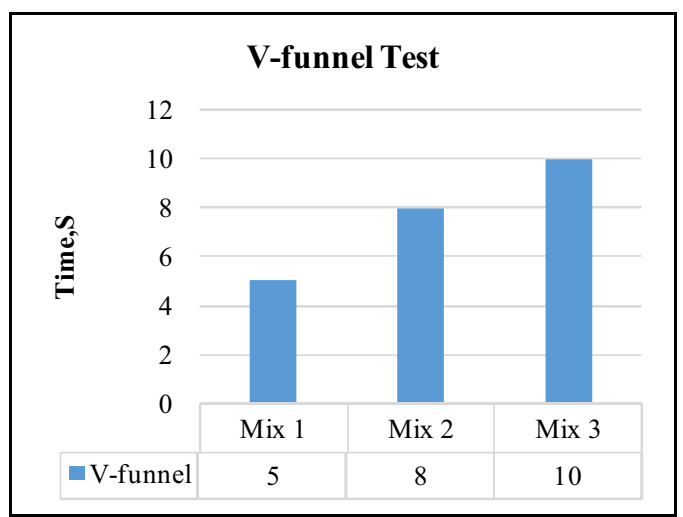

Fig. 3. The bar graph of V-funnel result.

Table 3 shows the result of the V-Funnel test for each selected mixture in this experiment. The measurement of time through V-Funnel test was ranging from 5 to 10 seconds affected by the type of mixture used for each case. A lower flow time of 5 seconds was recorded for the free PPF mixture, while the SCC had highest flow time of 10 seconds. The graphical result is shown in Fig. 3. 


\subsection{Mechanical properties}

\subsubsection{Compressive strength}

Fig. 4 demonstrates the values of compressive strength test for each mixture. Using different PP fibres proportions has indicated vital change in the related results. Increasing the PP fibres in the experiment has shown an enormous increase in the compressive strength values. This change can be justified that the PP fibre is preventing any further extension of cracks as well as reducing the stress extension at the edge of cracks. Another study confirmed the optimistic role of PP fibre in preventing and delaying any extension of cracks [12]. Higher compressive strength attained is due to higher efficiency of PP fibres in bridging the macro-cracks developed in the concrete [13]. The greatest value of compressive strength was attained by the mixture containing $0.9 \mathrm{~kg} / \mathrm{m}^{3} \mathrm{PP}$ fibres.

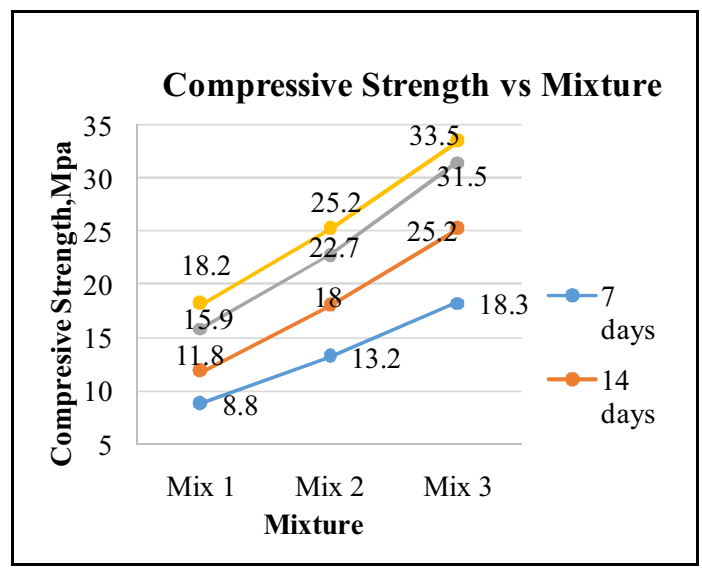

Fig. 4. Compressive strengths values of different PP fibre content.

\subsubsection{Splitting tensile and strength flexural strength}

The test of splitting tensile was performed as described in the British Standard [14] by using a $150 \mathrm{~mm} \times 300 \mathrm{~mm}$ cylinder at the age of 28 days.

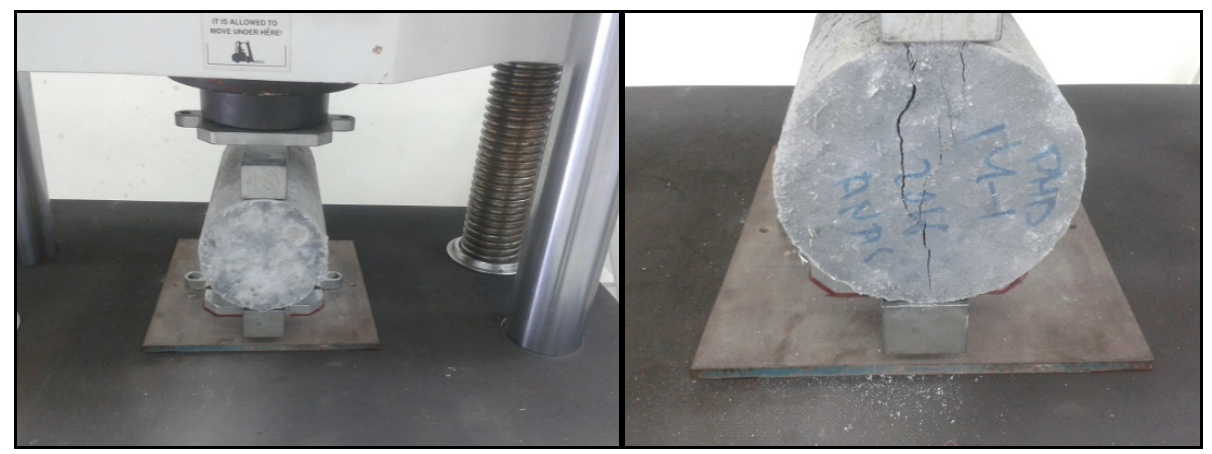

Fig. 5. Test of splitting tensile. 
Flexural experiment was conducted using $100 \mathrm{~mm}$ x $100 \mathrm{~mm}$ x $500 \mathrm{~mm}$ concrete beams as prescribed in British Standard [15] at the age of 28 days. The flexural strength is calculated by means of constant moment in the central zone of the specimen using two-point loading with a loading rate from the testing machine of $0.04 \mathrm{~N} / \mathrm{mm}^{2} / \mathrm{sec}$.

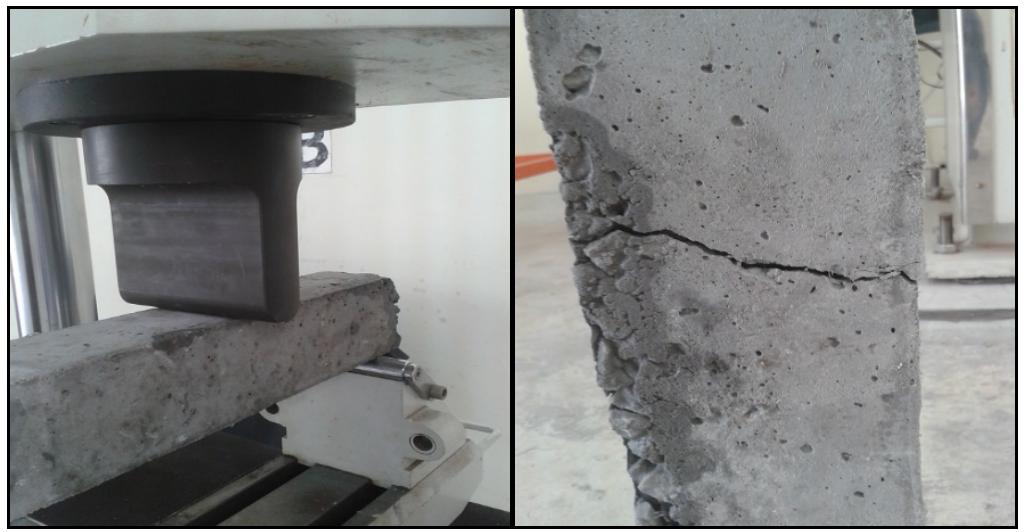

Fig. 6. Flexural test and specimen.

Three ages were considered for testing in this study, 7, 28 and 56 days. Splitting tensile and flexural strength tests were evaluated in many mixture proportions. Fig 7 and 8 illustrate the values of the selected tests accordingly. It was noticed that increasing the PP fibres proportion has led to an increase in the splitting tensile strength values. This tendency was reported in previous study [12]. It can be noticed that increasing the addition of PP fibres from 0.45 to $0.9 \mathrm{~kg} / \mathrm{m}^{3}$ has affected the splitting tensile strength values from 2.8 to 3.2 Mpa respectively. Results, in general, indicated the improvement of SCC by the adding of PP fibres to the mixture.

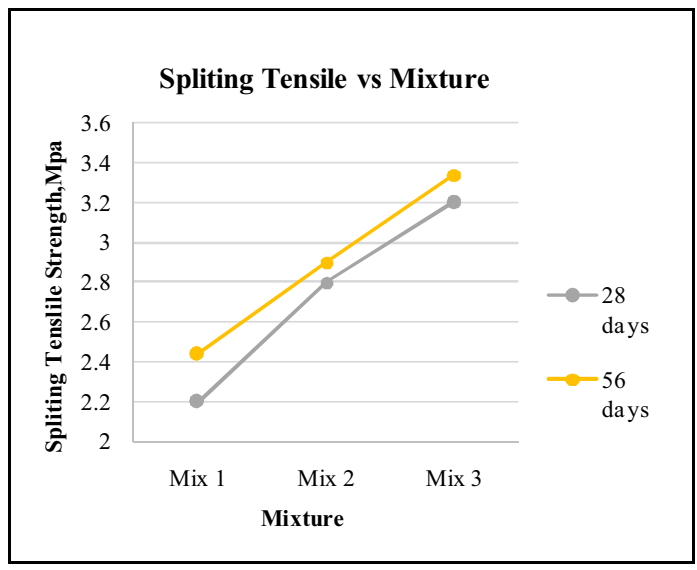

Fig. 7. Tensile strengths of different polypropylene fiber content.

Also, there has been recorded that the addition of PP fibres in the concrete was advantageous and has an enormous role in the flexural strength test. Fig. 8 shows the increased reading of flexural strength test from 2.8 to 3.7 Mpa when adding the PP fibres to the mixture. 


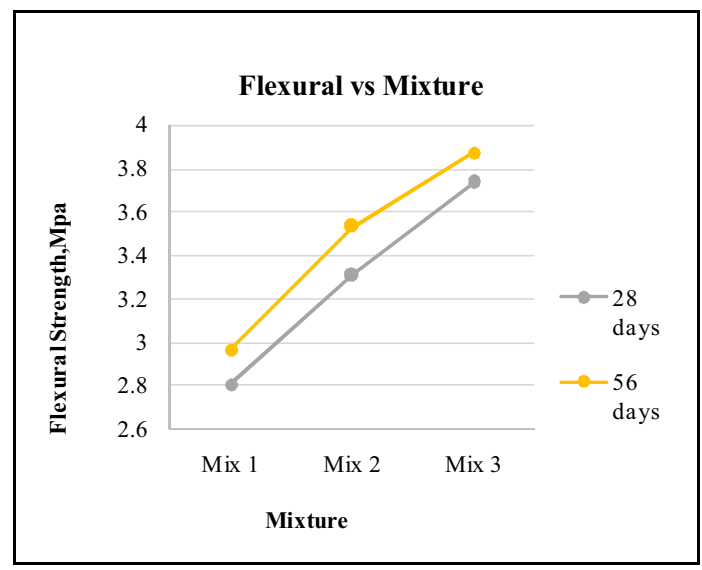

Fig. 8. Flexural strengths of different polypropylene fiber content.

\section{Conclusion}

The workability of the SCC concrete with PP fibres has shown a considerable decrease with increasing the PP fibres dosage. As tested in the mechanical experiments, adding PP fibres has resulted in much more strong concrete and more crack resistant concrete. The optimum percentage of PP with adequate strength was found to be about $0.9 \mathrm{~kg} / \mathrm{m}^{3}$, as this has been confirmed due to the highest compressive strength value in SCC mixture with 0.9 $\mathrm{kg} / \mathrm{m}^{3}$ of PP fibres which is $31.5 \mathrm{Mpa}$ at 28 days. Also, it was noticed that increasing the PP fibre content has led to a noticeable enhancement in mechanical properties of concrete. It is believed that PP fibres has shown its ability at preventing any further extension of cracks as well as reducing the stress extension at the edge of cracks.

The authors gratefully acknowledge the financial support of Higher Ministry of Education and Universiti Tun Hussein Onn Malaysia. (FRGS Vot 1525)

\section{References}

[1] H. Okamura, M. Ouchi, Self-compacting concrete. J. of Advance Concrete Technology. Japan Concrete Institute, 1(5), 5-15, (2003)

[2] T.Ch. Mahdavi, L. Swamy Raju and D. Mathur, Polypropylene fiber reinforced concrete- a review, Int. Conf. (ACECIM), 114-119, (2014)

[3] Z. Bayasi and M. McIntyre, Application of fibrillated polypropylene fibers for restraint of plastic shrinkage cracking in silica fume concrete, ACI Materials J., 99, 337-344 (2002)

[4] S.P. Shah, S.E. Swartz and C. Ouyang, Fracture mechanics of concrete, John Wiley \& Sons, Inc., New York, USA, (1995)

[5] BS 1881: Part 114, Determination of density of hardened concrete, British Standard Association (1983)

[6] BS 1881: Part 116, Method for determination of compressive strength of concrete cubes, British Standard Institution (1983)

[7] M. Sonebi, Medium strength self-compacting concrete containing fly ash, Cement and Concrete Research, 34,1199-1208, (2004) 
[8] N. Bouzoubaâ, M. Lachemi, Self-compacting concrete incorporating high volumes of class f fly ash, Cement and Concrete Research, 31(3), 413-420, (2001)

[9] K. Ozawa, N. Sakata, H. Okamura, Evaluation of self-compact ability of fresh concrete using the funnel test, Proc. Japan Society of Civil Engineering, 59-75, (1995)

$[10]$ K. Khayat, A. Ghezal, S. Hadriche, Factorial design model for proportioning selfconsolidating concrete, Materials and Structures, 32(9), 679-686, (1999)

[11]EFNARC-The European Guidelines for Self-Compacting Concrete: Specification, Production, The European Federation of Specialist Construction Chemicals and Concrete Systems, (2005)

[12] V. Afroughsabet and T. Ozbakkaloglu, Mechanical and durability properties of highstrength concrete containing steel and polypropylene fibers, Construction and Building Materials, 38(3), 389-404, (2015)

[13] M. Hsiea, C. Tua and P. Songb, Mechanical properties of polypropylene hybrid fiberreinforced concrete, J. Materials Science and Engineering, 27, 297-306, (2008)

[14]BS 1881: Part 117, British Standard Institution, Method for determination of compressive strength of concrete cubes, British Standard Association, (1983)

[15]BS 1881: Part 118, Method for determination of compressive strength of concrete cube, British Standard Association (1983) 